\title{
Article \\ Lifecycle Assessment and Techno-Economic Analysis of Biochar Pellet Production from Forest Residues and Field Application
}

\author{
Richard Bergman ${ }^{1, *} \mathbb{0}$, Kamalakanta Sahoo ${ }^{1,2} \oplus$, Karl Englund ${ }^{3}$ and Seyed Hashem Mousavi-Avval ${ }^{1,2}$ \\ 1 Forest Products Laboratory, United States Forest Service, 1 Gifford Pinchot Drive, Madison, WI 53726, USA; \\ kamalakanta.sahoo@usda.gov (K.S.); seyedhashem.mousaviavval@usda.gov (S.H.M.-A.) \\ 2 Department of Biological Systems Engineering, University of Wisconsin-Madison, 460 Henry Mall, \\ Madison, WI 53706, USA \\ 3 Composite Materials and Engineering Center, Washington State University, 100 Dairy Road Pullman, \\ Washington, DC 99164, USA; englund@wsu.edu \\ * Correspondence: richard.d.bergman@usda.gov
}

Citation: Bergman, R.; Sahoo, K.; Englund, K.; Mousavi-Avval, S.H Lifecycle Assessment and Techno-Economic Analysis of Biochar Pellet Production from Forest Residues and Field Application. Energies 2022, 15, 1559. https:// doi.org/10.3390/en15041559

Academic Editor: Francesco Asdrubali

Received: 7 January 2022

Accepted: 17 February 2022

Published: 20 February 2022

Publisher's Note: MDPI stays neutral with regard to jurisdictional claims in published maps and institutional affiliations.

Copyright: (C) 2022 by the authors. Licensee MDPI, Basel, Switzerland. This article is an open access article distributed under the terms and conditions of the Creative Commons Attribution (CC BY) license (https:// creativecommons.org/licenses/by/ $4.0 /)$

\begin{abstract}
Biochar produced from low-value forest biomass can provide substantial benefits to ecosystems and mitigate climate change-induced risks such as forest fires. Forest residues from restoration activities and timber harvest and biochar itself are bulky and thus incur high logistic costs, so are considered major bottlenecks for the commercialization of the biochar industry. The objectives of this study were to assess the environmental footprints and techno-economic feasibility of converting forest residues in Pacific Northwest United States into biochar pellets using portable systems followed by delivery of the final product to end-users for land application (dispersion). Two portable systems (Biochar Solutions Incorporated (BSI) and Air Curtain Burner (ACB)) were considered for biochar production. A cradle-to-grave lifecycle assessment (LCA) and a discounted cash flow analysis method were used to quantify the environmental impacts and minimum selling price (MSP) of biochar. The global warming (GW) impact of biochar production through BSI and ACB was estimated to be 306-444, and 750-1016 $\mathrm{kgCO}_{2} \mathrm{eq} /$ tonne biochar applied to the field, respectively. The MSP of biochar produced through BSI and ACB was 1674-1909 and 528-1051 USD/tonne biochar applied to the field, respectively. Pelletizing of biochar reduced GW impacts during outbound logistics $(\sim 8-20 \%)$ but increased emissions during pelletizing $(\sim 1-9 \%)$. Results show the BSI system was a more viable option in terms of GW impact, whereas the ACB system can produce biochar with lower MSP. The results of the study conclude that the production of biochar pellets through the two portable systems and applied to fields can be both an environmentally beneficial and economically viable option.
\end{abstract}

Keywords: biochar pellet; forest residues; lifecycle assessment; minimum selling price; environmental impacts

\section{Introduction}

Intensive agriculture negatively affects soil organic matter and nutrient balances [1], which causes a reduction in land fertility, agricultural productivity, and consequently farmers' income, and thus increases the threat to the global food supply [2]. Although chemical fertilizers are one of the major factors for the green revolution, these have severe environmental impacts when applied in excess. Application of biochar in agricultural lands is considered as a potential solution to prevent loss of fertilizers to water bodies and enhance the soil quality by improving the soil organic carbon, and hence improving agricultural productivity [3]. One of the potential feedstocks for the production of biochar is forest residue [4]. In the United States, forest residues, a byproduct of timber harvest, have a high potential to be utilized as a biomass feedstock for renewable products $[5,6]$. According to the 2016 billion-ton report baseline scenario (assuming moderate growth in housing starts and low growth in biomass for energy), about 93.1 million dry tons of forest residues and whole-tree biomass from thinning operations and clear cutting will be 
available in 2022 [7]. Forest residues from restoration activities and timber harvests are typically left in the forest to degrade or pile and burn depending on the forest management practice subscribed [6]. In addition, forest residues left on-site increase the risk of wildfires and diseases; the majority of fires result from overstocked forest land (Dennison et al., 2014; USDOE, 2016). Consequentially, conversion of forest residues to a useful product, such as biochar, not only helps produce valuable biobased products but also reduces the risk of forest fires, which are becoming extreme due to increasing fuel loads in the forest, i.e., woody biomass [8]. It also reduces the need for controlled pile and burning of forest residues, which causes air pollution and damages human health [9]. Conversion of forest residues to biochar in the pellet form also helps to capture carbon from the environment and store it in the soil, thus reducing $\mathrm{CO}_{2}$ in the atmosphere, in addition to increasing soil productivity and enhancing soil carbon $[2,10]$.

The high cost of inbound (i.e., biomass) and outbound (i.e., biochar) logistics is one of the main obstacles to the commercialization of the biochar industry and its growth. Considering the low price of forest residues, they are considered as a potential feedstock for biochar; however, the wide geographic distribution of forest residues usually causes high costs of logistics operations, e.g., collection, loading, transportation, unloading, and storage $[4,11,12]$. In addition, forest residues usually have both low bulk and energy densities but high moisture content, which tends to generate a high cost for feedstock transportation, handling, and drying $[13,14]$. The use of portable systems for the conversion of forest residues to various biomass-based products at a point close to the supply regions can potentially reduce the biomass logistics costs $[4,15]$.

Biochar is often a dry powdery material that is difficult to handle and efficiently disperse. Through pelletizing, the bulk density of biochar is increased and the material is aggregated, thus reducing the logistics (i.e., transportation, storage, handling, and field application) costs $[16,17]$. In addition, converting biochar into pellets may improve total porosity and aeration porosity; thus, its proper balance in the soil can help the plant growth [18]. To reduce the cost of biochar logistics, pelletization has been recently considered as an alternative method for efficient handling and biochar application to soil $[16,19]$.

Few studies have evaluated the use of portable systems; however, their main focus is the production of bio-oil as the main product, but not biochar [20-23]. The current literature either lacks or does not provide holistic information on the technical feasibility, costs, and environmental impacts of biochar production and pelletizing using portable systems. Thus, the objective of this research was to assess the technical feasibility, costs, and environmental impacts of biochar pellet production through portable systems, and delivery of biochar pellets to end-users who applied the biochar to soil. This study considered two portable biochar production systems-Biochar Solutions Incorporated (BSI) and Air Curtain Burner (ACB) - that were developed, evaluated, and marketed in the US.

\section{Materials and Methods}

\subsection{System Description}

The cradle-to-grave system boundary is defined as having three main sections, namely, (1) forest residues harvest and post-harvest logistics operations, (2) biochar production in bulk or pellet form, and (3) biochar packaging, transportation, and field application (Figure 1), as described in the following sections.

\subsubsection{Harvest and Post-Harvest Logistics Operations}

This study covered the harvesting (extraction) of forest residues from conifer timberland during commercial logging operations for five harvesting sites in the US Pacific Northwest [24]. The average annual harvest yield of all five sites was estimated to be $\sim 82$ tonnes/ha (dry basis woody biomass). The study covered the collection and processing of forest residues. Different types of residues considered for this study included pulp logs, tree tops, and branches. Usually, the moisture content of fresh forest residues is around 
$50 \%(\mathrm{wb})$. Pulp logs are available because of the lack of markets which may not reflect other regions of the U.S. To aid in processing, the moisture content of forest residues from timber harvesting can be reduced to below $20 \%(\mathrm{wb})$ by sorting and field drying for a few months [25].

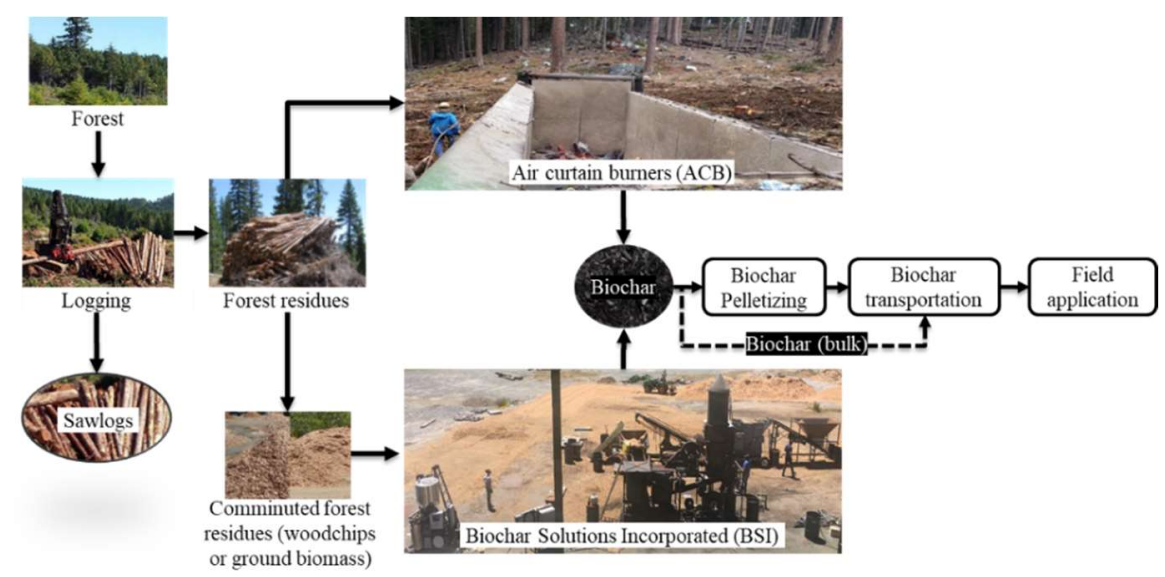

Figure 1. The supply chain of biochar production (ACB and BSI portable processing systems) and field applications.

The two portable biochar systems entail different handling and woody material. The BSI system requires a consistent size and quality of biomass, and thus chipping and screening were considered (at the near-forest processing site) to prepare feedstocks for biochar production. Using the BSI system, the residues were considered to be hauled from the timberland to the conversion site (near-forest processing site) using trucks with a maximum of one-hour hauling; whereas in the ACB system, the residues were processed in-forest at their source, logging sites (i.e., large piles of forest residues in the forest), with no need for feedstock transportation. In addition, ACB can process biomass with a wide range of moisture content. Furthermore, unlike the BSI system, biomass size and quality are less of an issue for ACB, so the system can process large chunks of forest residues in its bin. Therefore, for the ACB system, this study did not consider any feedstock transport and preprocessing [26].

\subsubsection{Biochar Production Systems}

Two portable platforms of BSI and ACB (Figure 2) setups were analyzed for this study. Biochar produced from these systems was either stored as bulk (powder) or compressed into pellets. This study used a mass allocation approach to contribute to the felling and yarding impacts of timber harvesting between the sawlogs and forest residues. Sawlogs were outside the system boundary so their impacts were not considered. 


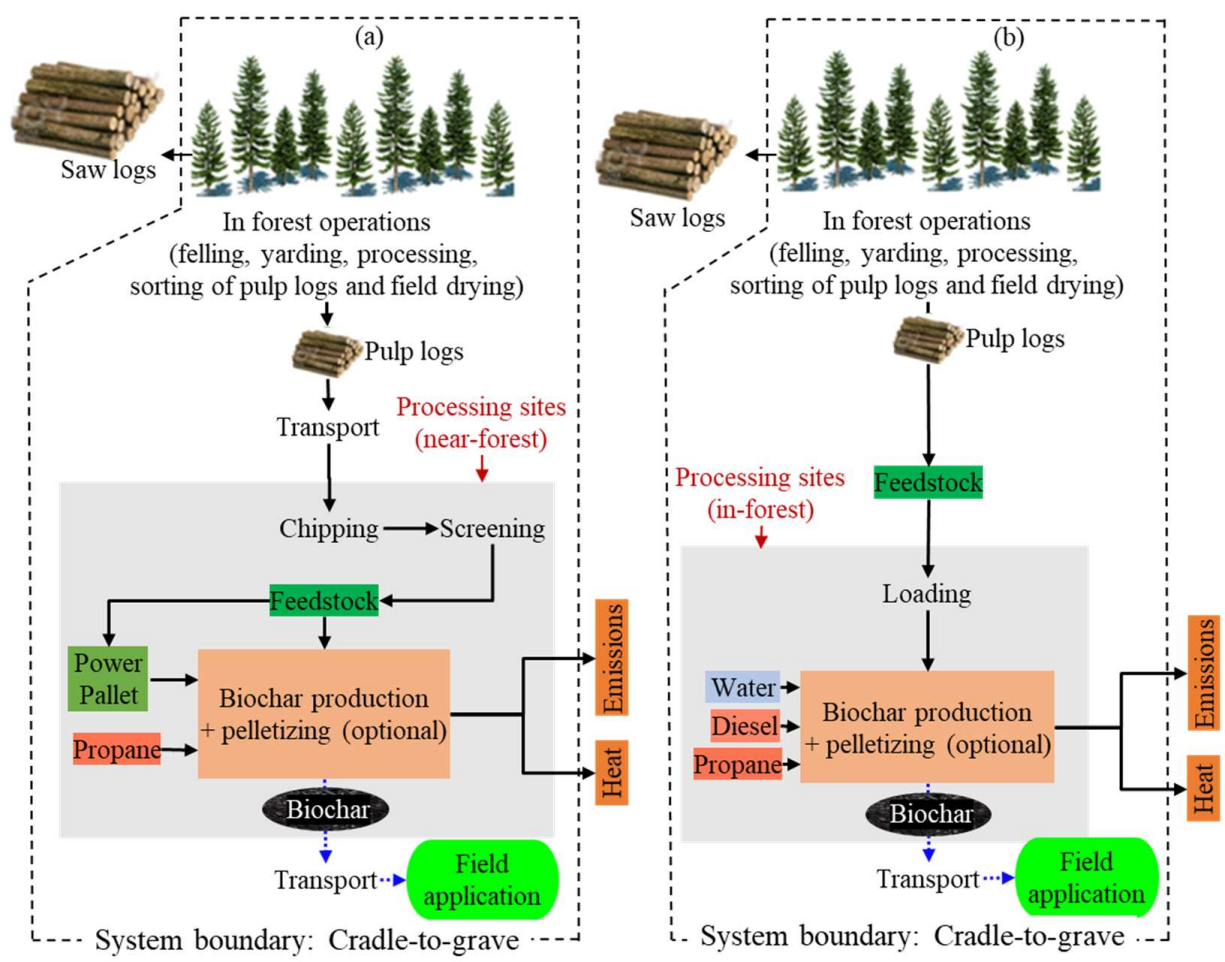

Figure 2. Forest residue logistics and biochar (pellet) processing through (a) Biochar Solutions Incorporated and (b) Air Curtain Burner [27].

The BSI system (Figure 2a) is used for biochar production at near-forest locations. This system is a continuously operating process. The chipped and screened wood chips are usually field-dried to around $21 \%(\mathrm{wb})$, and thus do not require additional drying before being fed into the BSI system for producing biochar. The operating rate of the BSI system under study is $267 \mathrm{~kg} / \mathrm{h}$ of woody biomass, which can produce $35 \mathrm{~kg} / \mathrm{h}$ of biochar [28]. Two BSI systems were considered at one site to optimize the use of labor and other logistics resources [26]. Electricity needs for operating the BSI system at the near-forest locations are usually supplied through two woody gasifier-based generators (i.e., Power Pallet, $\sim 20 \mathrm{~kW}$ ). The operating temperature for biochar production through the BSI system was $680-750^{\circ} \mathrm{C}$ [26]. More details of biochar production using the BSI system are provided in the literature [28]. The performance data for the BSI system was obtained from Schatz Energy Research Center (SERC), Humboldt State University, where the system was tested [28].

In the ACB system (Figure 2b), the woody biomass is burned to ash in refractory-lined boxes, equipped with powerful blowers [26]. The in-forest ACB system considered for this study had a bin size that was $9.2 \mathrm{~m}$ long, $2.6 \mathrm{~m}$ wide, and $2.6 \mathrm{~m}$ high (S-220 model), and a blower operated with a $36 \mathrm{~kW}$ diesel engine. The operating temperature of the ACB system was similar to that of the BSI system. The ACB system, in contrast with the BSI system, is capable of handling biomass with a larger length, up to the length of the ACB system (i.e., $9.2 \mathrm{~m}$ ); thus, there is no need for biomass preprocessing. The ACB system was operated in batch mode where an excavator loaded the woody biomass into the bin. For this study, the $\mathrm{ACB}$ unit ran under pyrolysis mode for the production of biochar from the forest residues; thus, the blower was not needed. The ACB system can process about 10 tonnes of biomass $(21 \%(\mathrm{wb}))$ and produce about $536 \mathrm{~kg}$ of biochar in an hour. Once the batch was complete, the hot biochar was unloaded from the ACB system and quenched using water. Overall, biochar produced through the ACB system had higher carbon fixation compared to that of the BSI system. More details on biochar production through the ACB system are provided in the literature [26,27]. 
To aggregate the powder-based material from biochar production systems such as BSI or $\mathrm{ACB}$, an onsite pelletization system compresses the fine biochar powder produced from both systems into pellets. It was estimated that pelletizing of biochar typically requires about $61.47 \mathrm{kWh}$ of electricity per oven-dry tonne (ODT) [16]. The processing capacity of biochar pelletizing equipment was similar to the biochar production capacity of both BSI and ACB systems. For the BSI system, the same power source (i.e., Power Pallet) provided electricity to the pelletizing equipment. However, we assumed a diesel generator to power the pelletizing equipment for biochar produced by ACB. The capacity, power consumption, and cost of pelletizing equipment are provided in Section 2.2.1. The bulk densities of biochar in powder and pellet forms were considered to be 98.7 and $287 \mathrm{~kg} / \mathrm{m}^{3}$, respectively.

\subsubsection{Biochar Packaging, Transport, and Field Application}

The system description for production of biochar pellets from bulky biochar is provided in the literature [16]. Biochar packaging is needed before transportation to the field. Either biochar powder or biochar pellets were considered to be packaged in sack bags and transported in trucks for a maximum distance of $50 \mathrm{~km}[16,29,30]$.

Details on the application of biochar pellets in forestry soils are provided in the literature [16]. Biochar pellet application in agricultural lands was considered to be similar to solid manure application [30]; thus, similar farming equipment was considered for land application of biochar in this analysis.

\subsection{Modeling Framework}

A lifecycle assessment (LCA) approach was used to estimate the environmental impacts of biochar produced from forest residues, making biochar pellets (optional), and applied to the soil. Techno-economic analysis was used to evaluate the technical feasibility and costs of biochar production systems. The primary data used in this study were compiled from the Waste to Wisdom (WTW) research project [6], where experiments were conducted for forest residue harvesting, feedstock preparation, and biochar production with portable systems. The experimental data for biochar pelletizing were taken from the literature [16]. There were several scenarios studied that considered types of feedstocks, production systems, processing location, and sources of electricity used in operating the production systems [27]. However, this study focused on the biochar production at the nearforest (with BSI system) or in-forest (with ACB system) sites and delivered to end-users for field application as powder or pellets.

For this analysis, forest residues were considered both as a waste, which is typical, and as a coproduct, which included the forest operations to harvest timber. Therefore, forest residues may or may not carry forward upstream impacts from forest operations to delineate this specific impact. Because the forest residues may or may not include upstream impacts, equipment use (ACB vs. BSI), and forms of biochar (powder vs. pellets), we assessed eight distinct scenarios along with their overall cradle-to-grave lifecycle impacts.

\subsubsection{Lifecycle Assessment}

LCA was conducted by following the ISO 14040 and ISO 14044 standards [31,32] to quantify the environmental impacts of biochar production systems. LCA consists of four iterative phases, i.e., goal and scope definition, lifecycle inventory (LCI) analysis, lifecycle impact assessment (LCIA), and interpretation. SimaPro 9.1 [33] was used for the analysis.

\section{Goal and Scope Definition}

The goal of this LCA study was to compare the lifecycle environmental impacts of biochar, as bulk (powder) or pellet forms, produced through two portable systems, i.e., BSI and ACB, and biochar applied to the soil. The system boundaries included forest residue harvest and collection, processing, handling, transportation/hauling, biochar production, pelletizing (optional), biochar transportation to the field, and field application (dispersion). Based on the defined scenarios (Section 2.3), the study considered the impacts 
of logging operations associated with the integrated handling of forest residues for future utilization [24]. The only product of the systems was biochar in bulk or pellet forms, and no by-product was considered for the analyses. The functional unit was considered to be one tonne of biochar, as bulk or pellet form.

\section{Lifecycle Inventory (LCI) Analysis}

LCI included the data related to inputs, products, and emissions for both BSI and ACB systems. Data were obtained from both primary sources, i.e., experimental works with the portable systems, and secondary sources, i.e., literature. The primary data included feedstocks inputs, electricity and fuel consumption, ancillary materials inputs, and biochar pellet production. Data related to forest residue collection systems, including harvest, collection, transportation, and comminution, in addition to machine productivity rates, came from the literature $[14,16,24,26]$, and these data were used to quantify the LCI related to fuel use and transportation requirements for forest residue harvesting and preprocessing (Table 1). Biochar production data related to the BSI portable system were provided by SERC [34], and the data related to the ACB portable system were pulled from the literature [24,26].

Table 1. Lifecycle inventories for the harvesting and preprocessing of one oven-dry tonne (ODT) of forest residues (pulp logs).

\begin{tabular}{cccc}
\hline & Unit & $\begin{array}{c}\text { Including } \\
\text { Forest Operations }\end{array}$ & $\begin{array}{c}\text { Excluding } \\
\text { Forest Operations }\end{array}$ \\
\hline $\begin{array}{c}\text { Harvesting } \\
\text { Diesel } \\
\text { Gasoline }\end{array}$ & $\mathrm{L}$ & 6.4 & 2.1 \\
$\begin{array}{c}\text { Forest residue transport } \\
\text { (harvesting to landing) } \\
\text { Preprocessing } \ddagger\end{array}$ & $\mathrm{L}$ & 0.12 & 0.04 \\
$\begin{array}{c}\text { Diesel } \\
\text { Gasoline }\end{array}$ & $\mathrm{km}$ & 19.2 & 19.2 \\
\hline
\end{tabular}

${ }^{\dagger}$ Forest operations included felling and yarding of pulp logs only. ${ }^{\ddagger}$ Preprocessing is needed only for production of biochar through the BSI system, and the ACB system does not require preprocessing. Preprocessing is the same regardless of whether forest operations are included or not.

The LCI related to the conversion of forest residues into biochar (in powder or pellet forms) is provided in Table 2. Pelletizing of powder biochar requires electricity, which is generated through the use of additional feedstock (woody biomass) in a gasifier-based genset for the BSI system or additional diesel for a diesel generator for the ACB system. Emissions during the system operations are in both indirect and indirect forms. For the BSI system, emissions were obtained from SERC [34], and included CO, propane, NOx, and $\mathrm{SO}_{2}$. For operating at the optimum conditions, adjustment of flow rates of oxygen into the flare was performed to lower the levels of emissions. Data related to emissions for the BSI and ACB systems were taken from [24,35], respectively.

Trucking was considered for transportation of biochar pellets from the production site to the application site, i.e., the field. The transportation distance was considered to be $50 \mathrm{~km}$ (Table 3). Biochar, in powder and pellet forms, was applied to the soil through a broadcasting method [16] using a tractor and spreader. Fuel consumption per tonne of biochar applied to the soil is provided in Table 3.

Lifecycle Impact Assessment

LCIA was performed using the Tools for the Reduction and Assessment of Chemical and other Environmental Impacts (TRACI) 2.1 methodology [36]. The TRACI method presents environmental impacts in ten categories, namely, global warming (GW), acidification, eutrophication, ecotoxicity, human health-carcinogenic and non-carcinogenic, ozone depletion, photochemical ozone formation, resource depletion, and respiratory effects; however, this study focuses on evaluating the GW impacts of two systems. 
Table 2. Lifecycle inventories related to onsite biochar production of one oven-dry tonne (ODT) of biochar (bulk or pellet forms) with Biochar Solution Incorporated (BSI) and Air Curtain Burner (ACB).

\begin{tabular}{|c|c|c|c|}
\hline & Unit & BSI & ACB \\
\hline \multicolumn{4}{|l|}{ Input resources } \\
\hline Feedstock & $\mathrm{kg}(\mathrm{OD})$ & 5932 & 15,385 \\
\hline Efficiency (biochar yield per ODT of forest residues) & $\%$ & $16.4 \%$ & $6.5 \%$ \\
\hline $\begin{array}{l}\text { Gasifier-based generator's } \\
\text { woody biomass input }\end{array}$ & $\mathrm{kg}$ & $707\left(+127^{\dagger}\right)$ & $\mathrm{N} / \mathrm{A}$ \\
\hline Diesel & $\mathrm{L}$ & 18 & $105(+23 \ddagger)$ \\
\hline Propane & $\mathrm{L}$ & 8 & 1 \\
\hline Water (for quenching) & $\mathrm{L}$ & 0 & 2000 \\
\hline \multicolumn{4}{|l|}{ Output products } \\
\hline Biochar (as bulk or pellets forms) & ODT & 1 & 1 \\
\hline Fixed carbon & $\%$ & 65 & 89 \\
\hline
\end{tabular}

Table 3. Upstream logistics for biochar as bulk or pellets for field application per oven-dry tonne (ODT) of biochar.

\begin{tabular}{cccc}
\hline & Unit & Biochar (Bulk) & $\begin{array}{c}\text { Biochar } \\
\text { (Pellets) }\end{array}$ \\
\hline $\begin{array}{c}\text { Transportation } \\
\text { Transport distance }\end{array}$ & $\mathrm{km}$ & 50 & 50 \\
Biochar application & & 9.8 & 3.4 \\
Diesel & $\mathrm{L}$ & 6.4 & 2.2 \\
Gasoline & $\mathrm{L}$ & & \\
\hline
\end{tabular}

The cradle-to-grave GW impact and carbon stored in the soil as the biochar ( $>100$ years) were considered for net-GW impact. This study considered that all labile carbon and a certain part of recalcitrant carbon in biochar will degrade within a 100-year time-frame [37]. Based on the literature [38], it is estimated that after 100 years of land application of biochar, $80.5 \%$ of carbon in the biochar will remain stable and the remaining $19.5 \%$ will be emitted to the atmosphere. Thus, biochar carbon stability for a 100 -year time-frame was considered to be $80.5 \%$, which was used to estimate the net-GW impact of biochar.

\subsubsection{Techno-Economic Analysis (TEA) Capital Cost}

Equipment purchase cost, economic lifetime, and the salvage values for BSI and ACB systems (Tables 4 and 5) were used to estimate the capital cost. The biomass availability and its locations mainly dictate the site preparation and installation costs for portable systems $[4,15]$. Thus, these costs were considered as fixed operating costs. A scaling factor of 0.6 was considered for equipment for which there are no cost data available at the required size [4].

\section{Operating Cost}

The operating cost of biochar pellet production included the expenses associated with insurance, property taxes, and repair and maintenance, which were assumed to be $1.5 \%$ of average annual investment, $0.2 \%$ of the equipment purchase cost, and $15 \%$ of straight-line depreciation of total capital cost, respectively [26]. Both systems were assumed to run for 300 days per year. The cost of relocation was considered based on the number of relocations for the biochar pellet production systems, which depends on the feedstock availability and the production capacity of portable systems. This study considered two relocations per year [9]. Consumables for biochar pellet production include propane (for maintaining the flame in the exhaust stack in the BSI system, and for igniting the fire in the ACB system), diesel (ACB: used in a diesel generator for loader and diesel generator, BSI: tractor for 
the handling of feedstocks), and water (for quenching biochar in ACB). Labor needed for the biochar pellet production systems included a technician (50 USD/h) and a driver (22.5 USD/h) for the loader in the ACB system. Benefits were $35 \%$ of annual salary, and miscellaneous costs, i.e., unpredictable and administrative costs, were considered to be $10 \%$ of annual salary, i.e., USD 80,000 . The annual operating costs of biochar production through two portable systems are summarized in Table 6.

Table 4. Capital costs of biochar pellet production using Biochar Solutions Incorporated system [26].

\begin{tabular}{ccccc}
\hline Equipment & No of Units & Purchase Price (USD) & Economic Lifetime (Year) & Salvage Value (\%) \\
\hline Tractor & 1 & 15,000 & 10 & $20 \%$ \\
Biochar production & 2 & 340,000 & 10 & $20 \%$ \\
machine & 1 & 19,899 & 10 & $20 \%$ \\
Pelletizer [39] & 2 & 25,000 & 10 & $10 \%$ \\
Gasifier genset & 745,000 & & \\
BSI: Biochar (bulk) production system ${ }^{1}$ & 764,899 & & \\
BSI: Biochar pellet production system ${ }^{2}$ & & & \\
\hline
\end{tabular}

${ }^{1}$ Excluding pelletizing equipment cost; ${ }^{2}$ Including pelletizing equipment cost, i.e., USD 19,899.

Table 5. Capital costs of biochar (bulk and pellet) production using Air Curtain Burner system [26].

\begin{tabular}{ccccc}
\hline Equipment & $\begin{array}{c}\text { No of } \\
\text { Units }\end{array}$ & $\begin{array}{c}\text { Purchase } \\
\text { Price (USD) }\end{array}$ & Economic Lifetime (Year) & $\begin{array}{c}\text { Salvage } \\
\text { Value (\%) }\end{array}$ \\
\hline Air curtain burner & 1 & 168,900 & 10 & $20 \%$ \\
CAT Loader & 1 & 432,268 & 10 & $20 \%$ \\
Pelletizer [39] & 1 & 62,864 & 10 & $20 \%$ \\
Generator & 1 & 39,250 & 10 & $10 \%$ \\
ACB: Biochar (bulk) production system ${ }^{1}$ & 601,168 & & \\
ACB: Biochar pellet production system ${ }^{2}$ & 703,283 & & \\
\hline
\end{tabular}

Excluding pelletizing equipment cost; ${ }^{2}$ Including pelletizing equipment cost, i.e., USD 62,864.

Table 6. Operating costs for two portable systems of biochar pellet production.

\begin{tabular}{ccccc}
\hline Descriptions & Units & BSI & ACB & Source \\
\hline Relocations & USD/year & 22,636 & 1368 & Estimated \\
Repair and & USD/year & $11,399\left(+307^{\dagger}\right)$ & 6132 & Estimated \\
maintenance & & $\left(+1042^{\dagger}\right)$ & \\
Consumables ${ }^{\ddagger}$ & USD/year & 8016 & $(+52,574$ & Estimated \\
Labor & USD/year & 166,800 & 83,400 & Estimated \\
Insurance and & USD/year & $14,433\left(+170^{\dagger}\right)$ & 13,222 & Estimated \\
miscellaneous & & $\left(+860^{\dagger}\right)$ & \\
\hline Total operating cost & USD/year & 223,284 & 436,696 & \\
& & $(+477)$ & $(+53,364)$ & \\
\hline
\end{tabular}

${ }^{\dagger}$ Consumables for BSI system included the fuel (5060 USD/year) used in the frontend loader (17 kW) for handling feedstocks [4], supplemental propane (920 USD/year) used to ignite the daily initial feedstock in the reactor and flaring in the emission control device [28], and other periodic consumables (2040 USD/year) required in the BSI system. Consumables for ACB included fuel (USD 239,239) used for handling equipment (CAT loader $145 \mathrm{~kW})$ and the fuel used in diesel generator $(55 \mathrm{~kW})$ to power pelletizing equipment (USD 52,504), supplemental propane (787 USD/year) to daily ignite the initial feedstock in the ACB, and other periodic consumables (11,994 USD/year) required in the ACB system. ${ }^{+}$Repair and maintenance of pelletizing setup; ${ }^{\ddagger}$ contribution from pelletizing setup. * Contribution from the use of fuel in the diesel generator to generate electricity for pelletizing process.

Cost of Logistics Operations (Inbound and Outbound)

The inbound logistics included pulp log harvesting (optional), processing, transport, and pre-processing of pulp logs at the processing site. The cost of pulp log harvesting was estimated to be 16.5 USD/ODT [25] which may be included and excluded based on the scenario definition by considering it as a waste or by-product. The cost of transportation of pulp logs from the staging site to the processing site $(19.2 \mathrm{~km})$ was estimated to be 
4.2 USD/ODT [14]. The chipping and screening of pulp logs at the biochar processing site was estimated to be 8 USD/ODT [14]. Overall, the total cost of feedstock supply at the biochar processing site for the BSI system was either 12.2 or 28.7 USD/ODT based on excluding and including cost incurred in forest operations of pulp logs. For ACB, the price of feedstock was either 0 or 16.5 USD/ODT based on excluding and including the cost incurred in forest operations of pulp logs. Assuming the $4 \mathrm{~h}$ transportation time (one-way travel for a distance of $160 \mathrm{~km}$ ), the outbound logistics costs of biochar as bulk and pellets were 42.35 USD/ODT and 19.8 USD/ODT, respectively. The costs of field application of biochar as pellets and bulk were estimated to be 4.3 USD/ODT of pellet biochar and 8.6 USD/ODT of bulk biochar, respectively.

\section{Financial Analysis}

The major assumptions for the financial analysis were (i) project life of 10 years, (ii) nominal discount rate of $16.5 \%$ (before finance and tax), (iii) annual inflation of $2 \%$ for costs and revenues, and (iv) income tax rate of $40 \%$. It was considered that $40 \%$ of the initial capital cost was financed through a bank loan (annual 6.51\% (nominal) interest rate for a term of 5 years) and the rest was equity for the full project planning period. The details of the assumptions can be found in the literature [26]. The analysis assumed that both portable systems operated $16 \mathrm{~h} /$ day ( 2 shifts $\times 8 \mathrm{~h} /$ shift) for 300 days annually. All capital and operating cost estimates were adjusted to the 2021 US dollar considering the Chemical Engineering Price of Construction Indices (CEPCI) and the Consumer Price Index (CPI).

A Discounted Cash Flow Rate of Return (DCFROR) model was used to estimate financial performances, specifically, the production cost and the minimum selling price (MSP) of biochar delivered to the end-users. DCFROR is a measure of the maximum interest rate that the project could pay and still break even by the end of the project life, and is estimated by solving the following equation [40]:

$$
\sum_{n=1}^{n=t} \frac{C F_{n}}{\left(1+i^{\prime}\right)^{n}}=0
$$

where: $C F_{n}$ represents the cash flow in year $n$; $t$ denotes the project life in year; and $I$ represents the DCFROR in percent/100. More details on financial analysis are presented in the literature [26].

\subsection{Scenario Description}

This study evaluated the performance of two portable systems (i.e., BSI and ACB), for biochar production from forest residues, from the perspectives of techno-economic and environmental impacts. In addition, the performance of the systems was compared in terms of the final product types (i.e., pellet vs. bulk biochar). The impact of inclusion or exclusion of forest operations in the system boundary on the performance of the systems was also evaluated. In this study, forest operations involved the impacts from felling and yarding of pulp logs only during the collection of forest residues for processing. Thus, the scenarios considered for each portable system were: Scenario 1: Field application of biochar in bulk form, excluding forest operations during logging; Scenario 2: Field application of biochar in bulk form, including forest operations during logging; Scenario 3: Field application of biochar in pellet form, excluding forest operations during logging; and Scenario 4: Field application of biochar in pellet form, including forest operations during logging. In addition, the analysis was performed by considering different unit operations on the LCA and TEA of biochar pellet, which were: A1: Forest operations; A2: Transport $(1 \mathrm{~h})$ of forest biomass from the harvesting site to biochar processing site; A3: Biochar (bulk) production with either the BSI or ACB system and pelletizing (optional); A4: Transport of biochar (bulk or pellets); and B1: Biochar (bulk or pellets) applied to the field. A sensitivity analysis was performed to estimate the impacts of variations in input parameters on the lifecycle assessment results (i.e., GW impact) and financial performance (i.e., MSP). 


\section{Results and Discussion}

\subsection{Global Warming Impact of Biochar Pellet Production through Portable Systems}

The cradle-to-grave GW impacts of four scenarios of biochar pellet production and application using BSI and ACB portable systems are presented in Figures 3 and 4, respectively. The GW impact of the BSI system varied from 306 to $444 \mathrm{kgCO}_{2} \mathrm{eq} /$ tonne of biochar (Figure 3).

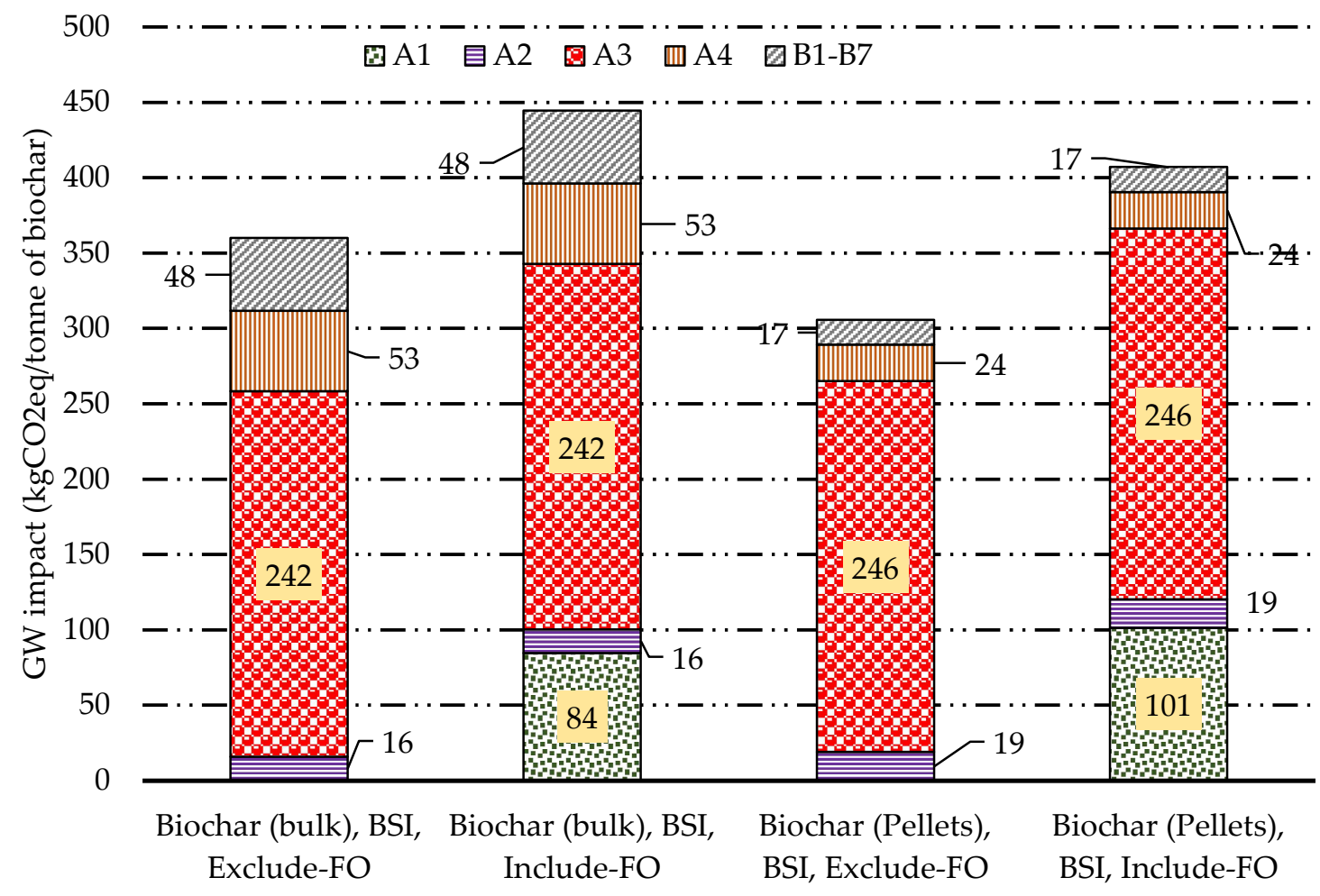

Figure 3. Global warming impacts of field application of biochar, in pellet and bulk forms, using the BSI system, by considering the impact of forest operations (FO). (Note: A1: Timber harvesting and forest biomass collection, A2: Transportation of forest biomass, A3: Production of biochar and pelletizing (optional), A4: Biochar transportation, and B1-B7: Biochar applied to soil and stored for more than 100 years).

Forest operation incurred about $84-101 \mathrm{kgCO}_{2} \mathrm{eq} /$ tonne of biochar $(20-25 \%)$ towards cradle-to-grave GW impacts of the BSI system. However, pelletizing can reduce the GW impacts by $37-54 \mathrm{kgCO}_{2} \mathrm{eq} /$ tonne of biochar ( 9-18\% of cradle-to-grave GW impacts), mostly due to the logistics of biochar. Among all scenarios analyzed for the BSI system, the second one, i.e., biochar as bulk, including forest operations during logging, had the highest GW (444 $\mathrm{kgCO}_{2}$ eq/tonne of biochar), whereas the third scenario, i.e., biochar as pellets, excluding forest operations during logging, had the lowest GW impact $\left(306 \mathrm{kgCO}_{2} \mathrm{eq} /\right.$ tonne of biochar). This indicates that the field application of biochar as pellets can potentially reduce (8-15\%) the GW impact, and, not unexpectedly, the inclusion of forest operations during logging increases the GW impacts.

Biochar produced with the ACB portable system at near-forest locations showed higher GW impact (2-2.5 times more) compared to the BSI system, with GW emissions from 750 to $1016 \mathrm{kgCO}_{2} \mathrm{eq} /$ tonne biochar applied to the field (Figure 4). This was mainly due to higher emissions during processing operations and lower biochar yield. The biochar production yield of ACB and BSI systems was estimated to be 35.6 and $126.8 \mathrm{~kg}$ biochar/tonne of woody biomass at $21 \%(\mathrm{wb})$, respectively. Hence, ACB requires more wood to be processed to obtain a similar amount of biochar compared to the BSI system. Among different scenarios considered, the GW impacts of scenarios 2 and 4 were higher than those of scenarios 1 and 3. This indicated that the differences in GW impact were mainly due to the inclusion and 
exclusion of forest operations, rather than the field application of biochar either as bulk or pellet forms.

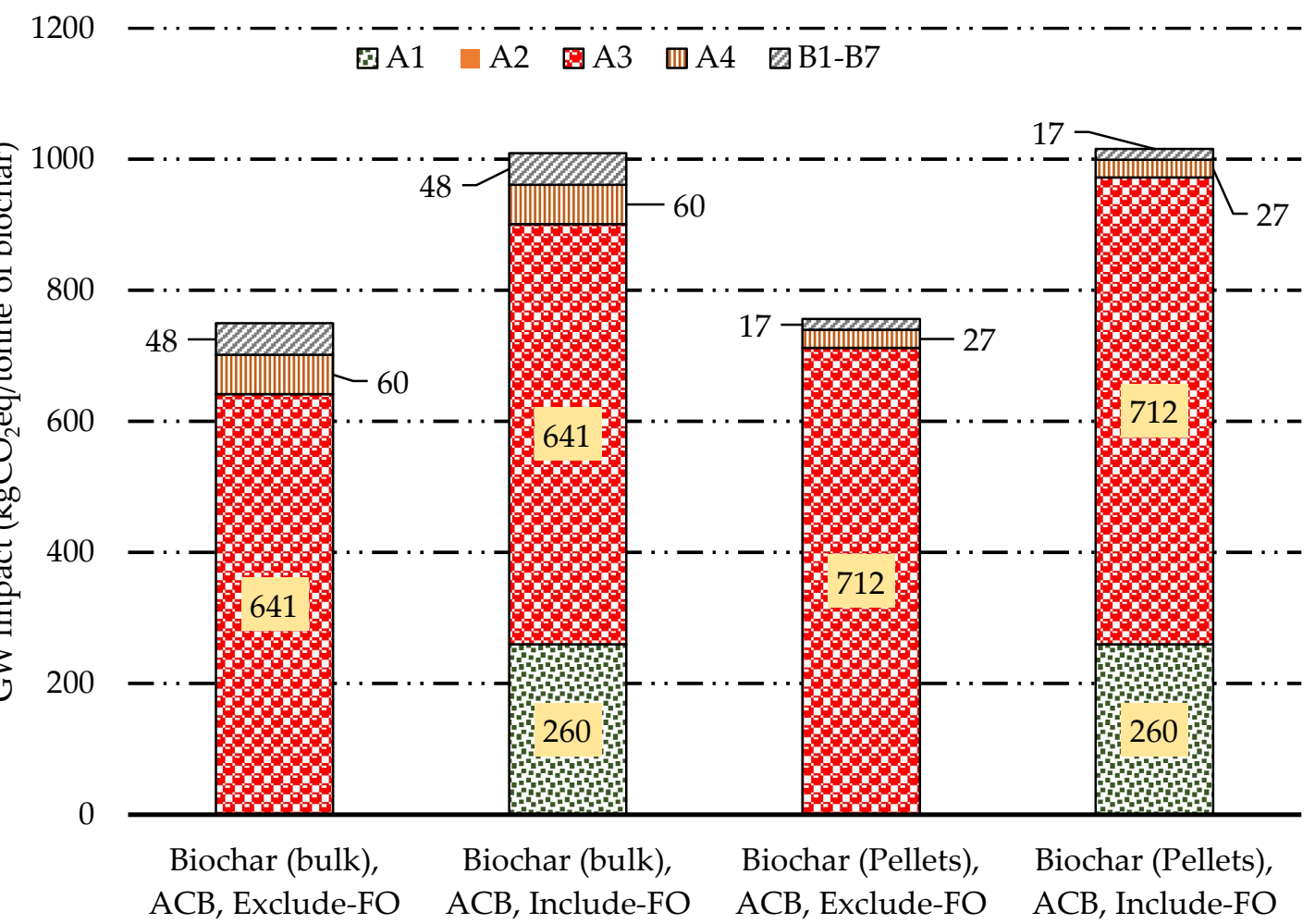

Figure 4. Global warming impact of field application of biochar, in pellet and bulk forms, using the ACB system, by considering the impact of forest operations. (Note: A1: Timber harvesting and forest residue collection, A2: Transportation of forest residues, A3: Production of biochar and pelletizing (optional), A4: Biochar transportation, and B1-B7: Biochar applied to soil and stored for more than 100 years).

Forest operation incurred about $\sim 26 \%$ of cradle-to-grave GW impacts of biochar production through the ACB system. Contrary to the BSI system, pelletizing increased the cradle-to-grave GW impacts by $6 \%$. This was due to the emissions associated with the high use of fuel in the diesel generator, which was about $71 \mathrm{kgCO}_{2} \mathrm{eq} /$ tonne biochar. Although pelletizing reduced the GW impacts in the products' transportation and biochar application process, which was about $64 \mathrm{kgCO}_{2} \mathrm{eq} /$ tonne biochar, pelletizing would be a better option for biochar if biochar pellets are transported for further distances, as assumed in this study. Among all scenarios analyzed for the ACB system, the fourth one, i.e., biochar as pellet, including forest operations during logging, had the highest GW impact ( $1015 \mathrm{kgCO}_{2} \mathrm{eq} /$ tonne of biochar), whereas the first scenario, i.e., biochar as bulk, excluding forest operations during logging, had the lowest GW impact ( $750 \mathrm{kgCO}_{2} \mathrm{eq} /$ tonne of biochar).

Figure 5 shows that, overall, field application of biochar for carbon sequestration reduced GW impacts substantially (by 2-6 times). Although the BSI system produced lower cradle-to-gate GW impacts, the carbon sequestration was lower due to lower carbon content in biochar for this system. Due to the high-quality biochar produced in the ACB system, the carbon storage capacity was much higher, and the net-GW impact was better. Overall, biochar production through portable systems reduced GW impacts by 1420-1800 kgCO $2 \mathrm{eq} /$ tonne of biochar (Figure 5), and thus can be considered as a carbonnegative solution. 


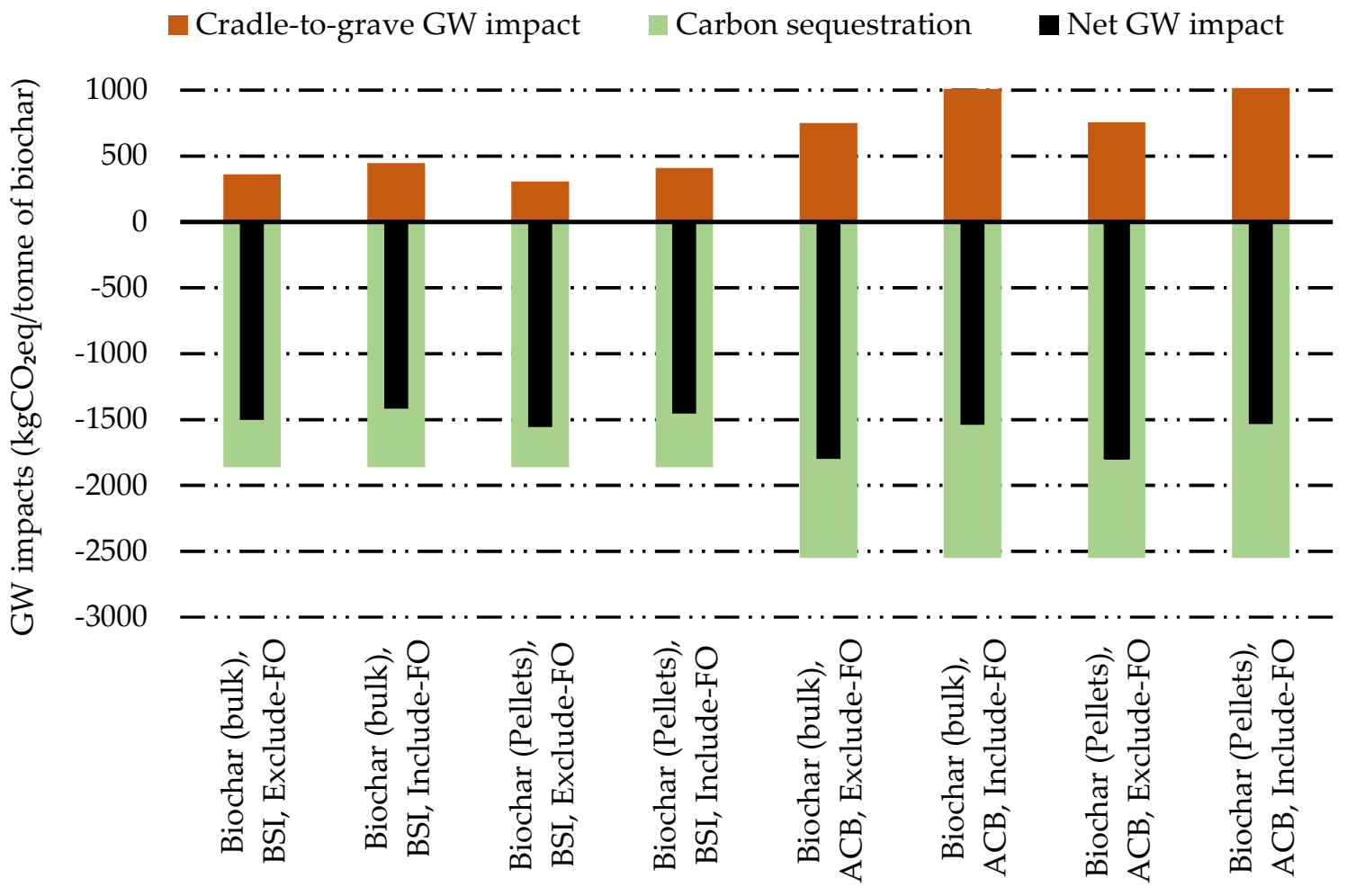

Figure 5. Overall global warming (GW) impacts of biochar (pellet and bulk) using the ACB and BSI portable systems.

\subsection{Techno-Economic Analysis of Biochar Pellet Production through Portable Systems}

The annual cost and MSP of biochar produced using the BSI system are presented in Figure 6 . The annual cost of biochar production through the BSI system was in the range of USD 412-470 thousand for different scenarios. Biochar pellet production, considering exclusion of forest operations during logging, had the lowest annual cost, whereas the highest cost was associated with biochar production as powder, considering the inclusion of forest operations during logging (Figure 6). Overall, the inclusion of forest operations during logging increased the annual cost, whereas field application of biochar as a pellet reduced the annual costs compared to application in bulk form. For all scenarios, capital cost and labor cost were the main components of annual production costs. In addition, 35\% (scenario 2) to $40 \%$ (scenario 4) of the annual cost was attributed to labor. The contribution of capital cost to total annual cost was slightly less than that of labor cost, which was estimated to be from 30\% (scenario 2) to 35\% (scenario 4). The MSP of biochar produced through the BSI system was in the range of 1674-1909 USD/tonne biochar, and it was lowest in biochar pellet production by considering exclusion of forest operations during logging and highest in biochar production as bulk by considering the inclusion of forest operations during logging (Figure 6).

The annual cost of biochar produced through the ACB system was in the range of USD 950-2050 thousand for different scenarios (Figure 7). Scenario 3 had the lowest cost (USD 950 thousand), whereas scenario 2 had the highest cost (USD 2050 thousand). The MSP of biochar produced through the ACB system was in the range of 528-1051 USD/tonne. Conversion of biochar to pellets and exclusion of forest operations during logging reduced the MSP of biochar in the ACB system. About 20-27\% (scenarios 1 and 3) and 52-60\% (scenarios 2 and 4) were due to feedstocks in scenarios where the forest operations were excluded and included, respectively. This was due to the very low yield of biochar in the ACB system, and thus required more woody biomass to be processed to offset this lower yield. 


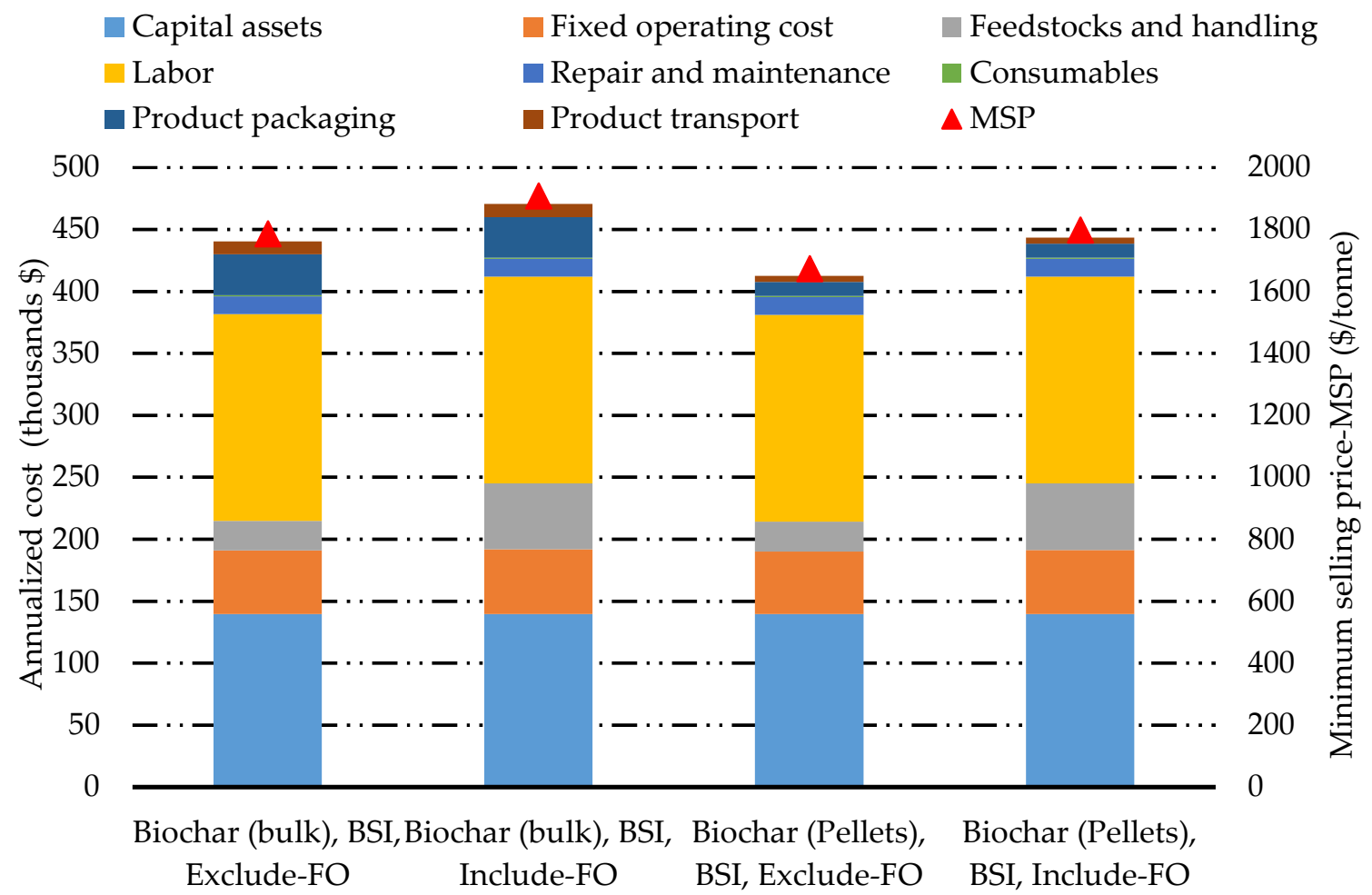

Figure 6. Annual cost and minimum selling price of biochar production, in pellet and bulk forms, through BSI portable system, by considering the impact of forest operations. Note: annual operating time was considered to be 100 days.

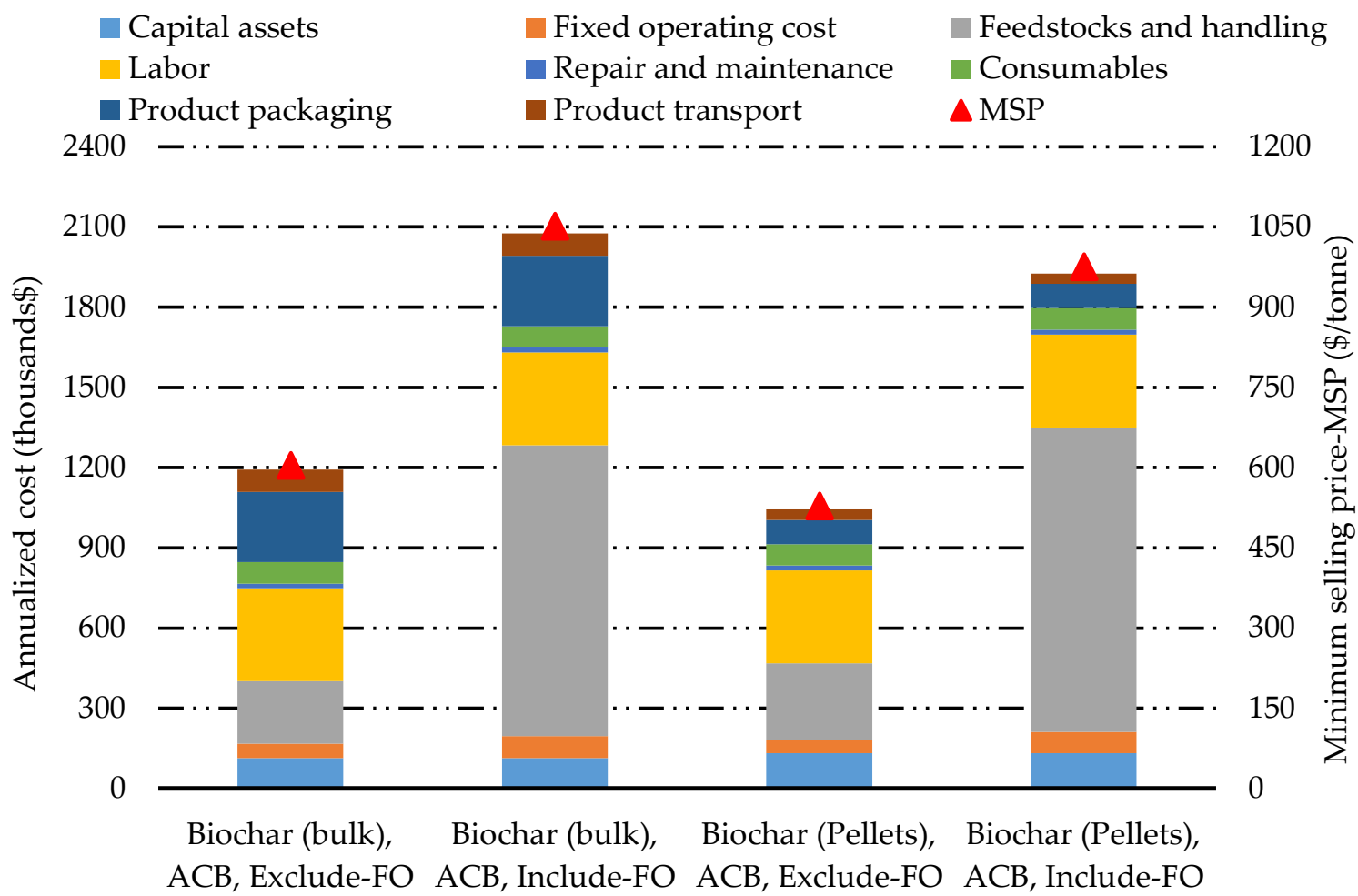

Figure 7. Annual cost and minimum selling price of biochar production, in pellet and bulk forms, through the ACB portable system, by considering the impact of forest operations. Note: annual operating time was considered to be 100 days. 
The comparison of the economics of BSI and ACB systems showed that the annual production cost of the ACB system is considerably higher than that of the BSI system, and this was mainly due to high costs of feedstock and handling, labor, and product packaging in the ACB system compared to the BSI system. Contrarily, the productivity or throughput of the ACB system was much larger than the BSI system, thus notably reducing the MSP for the ACB system.

Examining the MSPs in Figures 6 and 7, several conclusions can be made. First, biochar production in pellet form had lower MSP compared to biochar production in bulk form. Second, the inclusion of forest operations significantly affects the MSP in both BSI and ACB systems; however, the impact of inclusion and exclusion of forest operations in the ACB system was higher than that in the BSI system. This was mainly affected by feedstock and handling costs in the ACB system. Third, the BSI system had higher costs in terms of labor, and capital costs, which significantly increased the MSP of biochar produced in the BSI system compared to that of the ACB system. The productivity of ACB systems, such as the hourly production capacity of biochar, was much higher (by $\sim 5$ times) than the BSI system, thus helping to reduce the cost including capital and operational costs. From previous studies, the MSP of biochar production has been reported to be 838-1504 USD/tonne [41], and 774-1256 USD/tonne [42], depending on temperature, conversion rates, feedstock type, and price.

Biochar pellet production from forest residues can be considered as an expensive means of capturing or removing carbon from the atmosphere. However, these costs can be offset by incorporating United States Department of Agriculture Conservation Stewardship Program practices (e.g., E384135X). These practices align with the goal of using woody biomass after forest restoration activities. For example, the State of Washington has a financial incentive of 12,000 USD/ha [43], which would result in negative MSPs [26] for both BSI and ACB systems. In addition, there are several other environmental benefits of making biochar and applying it to the field, which include increasing soil quality and productivity. Furthermore, biochar can provide long-term storage for carbon that originated from trees pulling carbon dioxide from the atmosphere; thus, when biochar is added to the soil, carbon sinks, artificial reservoirs for accumulation of carbon dioxide, are formed and carbon sequestration occurs. Carbon sequestration potential during the lifecycle of biochar pellets in the soil can be estimated by taking into account the type of feedstock, biochar production conditions, biochar application, and soil management practices.

\subsection{Sensitivity Analysis Results}

Figure 8 shows the impacts of variations (20\% lower and 20\% higher in input values than the mean value for BSI and ACB) in the input parameters on life cycle assessment results (especially cradle-to-grave GW impacts) and financial performance such as minimum selling price (scenario 4 only). Among all input parameters, fuel use and biochar yield are the most influential input parameters affecting cradle-to-grave GW impacts of biochar produced in the BSI system. A 20\% lower fuel use in the harvesting and processing of forest biomass can reduce the GW impacts of biochar produced in the BSI system by $10 \%$ (Figure 8a). However, a 20\% lower biochar yield in the BSI system can increase the GW impacts of biochar by $24 \%$. Similar trends can be seen for biochar produced through the ACB system (Figure 8b).

Figure $8 c$,d show the variations in the MSP due to a $20 \%$ change (increase or decrease) in input parameters. Among all input parameters affecting the MSP of biochar pellets, the most influential input parameters were biochar yield, operational cost, and feedstock costs, which are common to both BSI and ACB systems. The operational days in a year and operational hours had higher impacts for the BSI than the ACB system. These results may guide the stakeholders, such as a biochar producers, to prioritize their focus on parameters to improve environmental impacts of biochar pellets and financial performances of BSI and ACB systems. 
BSI

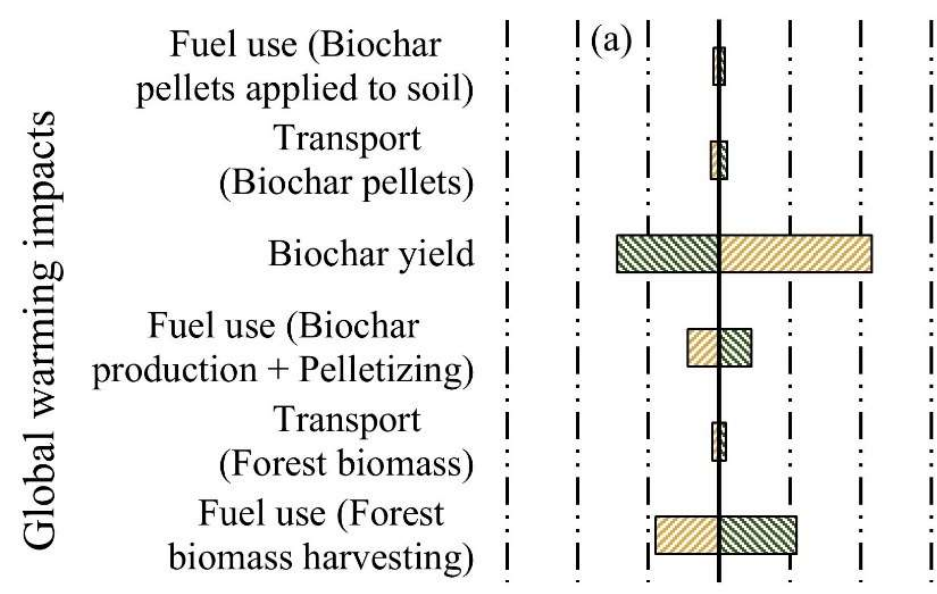

$-30 \%-20 \%-10 \% \quad 0 \% \quad 10 \% \quad 20 \% \quad 30 \%$
$\mathrm{ACB}$

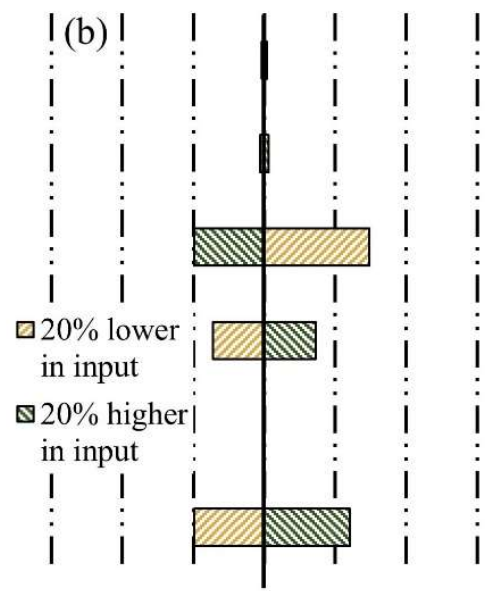

$-30 \%-20 \%-10 \% \quad 0 \% \quad 10 \% \quad 20 \% 30 \%$
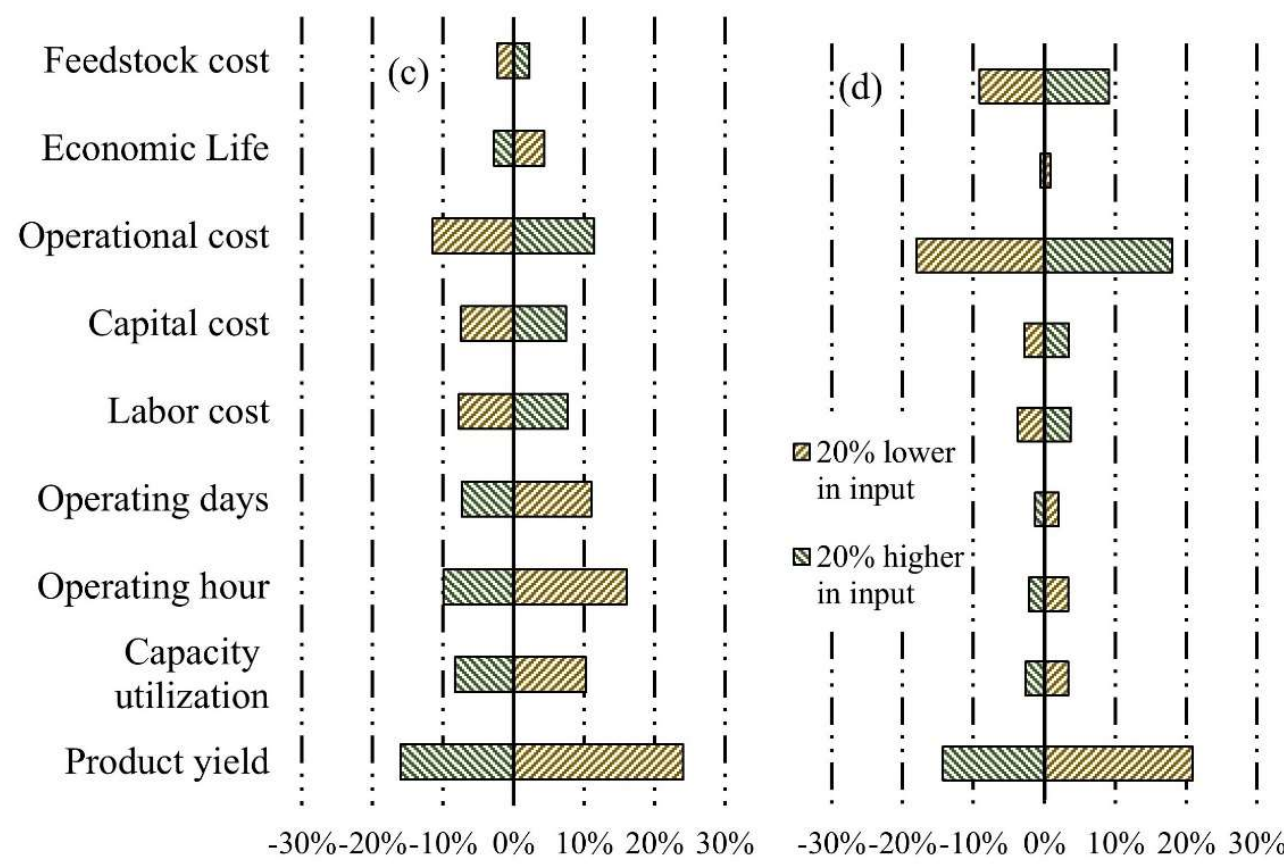

Figure 8. Sensitivity analysis results: Impacts of variations in input parameters on the cradle-to-grave global warming impacts $(\mathbf{a}, \mathbf{b})$ and minimum selling price $(\mathbf{c}, \mathbf{d})$ of biochar produced through BSI $(\mathbf{a}, \mathbf{c})$ and ACB (b,d) systems (scenario 4$)$.

\section{Conclusions}

The primary objective of this study was to assess the environmental impacts and economic costs of biochar production using portable systems and field applications. LCA and TEA of biochar pellet production from forest residues through BSI and ACB portable systems were evaluated. Overall, the cradle-to-grave GW impact of biochar pellets production using the BSI system (i.e., 306-444 $\mathrm{kgCO}_{2} \mathrm{eq} /$ tonne biochar) was substantially less than that of the ACB system (i.e., 750-1016 $\mathrm{kgCO}_{2} \mathrm{eq} /$ tonne biochar). In addition, biochar production through the ACB system had lower MSP compared to that of BSI (528-1051 vs. 1674-1909 USD/tonne biochar). Thus, the BSI system was revealed to be a more viable option in terms of GW impact, whereas the ACB system can produce biochar with lower MSP. In addition, conversion of biochar to pellets was found to reduce the overall GW impacts and MSP of biochar production. It is concluded that the production of biochar 
pellets from forest residues with portable systems is an environmentally beneficial and economically viable solution.

Considering the vast area of forests requiring restoration, the BSI system would be considered the best option given its lower GW profile, costs, and MSP. However, the production capacity of the systems and potential scaling up need to be considered. The outcomes of this study can provide critical information for the sustainable development of biochar production and application systems, and it is useful for all stakeholders, including policymakers, investors, forest owners, and farmers.

Author Contributions: Conceptualization, R.B., K.S. and K.E.; methodology, R.B. and K.S.; software, K.S. and S.H.M.-A.; validation, R.B., K.E. and S.H.M.-A.; formal analysis, R.B., K.S., S.H.M.-A. and K.E.; investigation, R.B., K.S., S.H.M.-A. and K.E.; resources, R.B.; data curation, R.B., K.S. and S.H.M.-A.; writing—original draft preparation, R.B., K.S. and S.H.M.-A.; writing—review and editing, R.B., K.E., S.H.M.-A. and K.E.; visualization, R.B. and K.S.; supervision, R.B.; project administration, R.B.; funding acquisition, R.B. and K.E. All authors have read and agreed to the published version of the manuscript.

Funding: This work is supported by Agriculture and Food Research Initiative Competitive Grant no. 2020-68012-31881 and no. 2011-10006-30357 from the USDA National Institute of Food and Agriculture. This work is also supported by a grant from the U.S. Department of Energy under the Biomass Research and Development Initiative program: Award Number DE-EE0006297 and a joint venture agreement between the USDA Forest Service Forest Products Laboratory and the U.S. Endowment for Forestry \& Communities, Inc., Endowment Green Building Partnership—Phase 1, no. 18-JV-11111137-021.

Institutional Review Board Statement: Not applicable.

Informed Consent Statement: Not applicable.

Data Availability Statement: The authors of this paper are employees of the United States Department of Agriculture, U.S. Forest Service. The findings and conclusions in this report are those of the author(s) and should not be construed to represent any official USDA or U.S. Government determination or policy. This research was supported in part by the U.S. Department of Agriculture, Forest Service. Any use of trade, firm, or product names is for descriptive purposes only and does not imply endorsement by the U.S. government.

Acknowledgments: We gratefully acknowledge the support given by the funding agencies and internal reviewers (Poonam Khatri at the USDA Forest Products Laboratory and David Nicholls at the USDA Pacific Northwest Research Station).

Conflicts of Interest: The authors declare no conflict of interest. The funders of this study and industry partners providing biochar had no role in the design of the study; in the collection, analyses, or interpretation of data; in the writing of the manuscript, or in the decision to publish the results.

\section{References}

1. Scotti, R.; Bonanomi, G.; Scelza, R.; Zoina, A.; Rao, M.A. Organic Amendments as Sustainable Tool to Recovery Fertility in Intensive Agricultural Systems. J. Soil Sci. Plant Nutr. 2015, 15, 333-352. [CrossRef]

2. Agegnehu, G.; Srivastava, A.K.; Bird, M.I. The Role of Biochar and Biochar-Compost in Improving Soil Quality and Crop Performance: A Review. Appl. Soil Ecol. 2017, 119, 156-170. [CrossRef]

3. Aller, D.M.; Archontoulis, S.V.; Zhang, W.; Sawadgo, W.; Laird, D.A.; Moore, K. Long Term Biochar Effects on Corn Yield, Soil Quality and Profitability in the Us Midwest. Field Crops Res. 2018, 227, 30-40. [CrossRef]

4. Sahoo, K.; Bilek, E.; Bergman, R.; Mani, S. Techno-Economic Analysis of Producing Solid Biofuels and Biochar from Forest Residues Using Portable Systems. Appl. Energy 2019, 235, 578-590. [CrossRef]

5. Tilman, D.; Socolow, R.; Foley, J.A.; Hill, J.; Larson, E.; Lynd, L.; Pacala, S.; Reilly, J.; Searchinger, T.; Somerville, C.; et al. Beneficial Biofuels-The Food, Energy, and Environment Trilemma. Science 2009, 325, 270-271. [CrossRef] [PubMed]

6. Bergman, R.; Berry, M.; Bilek, E.T.; Bowers, T.; Eastin, I.; Ganguly, I.; Han, H.-S.; Hirth, K.; Jacobson, A.; Karp, S. Waste to Wisdom: Utilizing Forest Residues for the Production of Bioenergy and Biobased Products; 78: Biomass Research and Development Initiative Program Award Number DE-EE0006297; US Department of Energy: Washington, DC, USA, 2018.

7. USDOE. 2016 Billion-Ton Report: Advancing Domestic Resources for a Thriving Bioeconomy, Volume 1: Economic Availability of Feedstocks; Stokes, B.J., Langholtz, M.H., Eaton, L.M., Eds.; ORNL/TM-2016/160; Oak Ridge National Laboratory, U.S. Department of Energy: Oak Ridge, TN, USA, 2016. 
8. Cook, P.S.; Becker, D.R. State Funding for Wildfire Suppression in the Western Us; University of Idaho: Moscow, ID, USA, 2017; 70p.

9. Berrill, J.P.; Han, H.S. Carbon, Harvest Yields, and Residues from Restoration in a Mixed Forest on California's Coast Range. For. Sci. 2017, 63, 128-135. [CrossRef]

10. Jeffery, S.; Bezemer, T.M.; Cornelissen, G.; Kuyper, T.W.; Lehmann, J.; Mommer, L.; Sohi, S.P.; van de Voorde, T.F.; Wardle, D.A.; van Groenigen, J.W. The Way Forward in Biochar Research: Targeting Trade-Offs between the Potential Wins. GCB Bioenergy 2015, 7, 1-13. [CrossRef]

11. Wright, M.M.; Daugaard, D.E.; Satrio, J.A.; Brown, R.C. Techno-Economic Analysis of Biomass Fast Pyrolysis to Transportation Fuels. Fuel 2010, 89, S2-S10. [CrossRef]

12. Yazan, D.M.; van Duren, I.; Mes, M.; Kersten, S.; Clancy, J.; Zijm, H. Design of Sustainable Second-Generation Biomass Supply Chains. Biomass Bioenergy 2016, 94, 173-186. [CrossRef]

13. Parkhurst, K.M.; Saffron, C.M.; Miller, R.O. An Energy Analysis Comparing Biomass Torrefaction in Depots to Wind with Natural Gas Combustion for Electricity Generation. Appl. Energy 2016, 179, 171-181. [CrossRef]

14. Sahoo, K.; Bilek, E.; Bergman, R.; Kizha, A.R.; Mani, S. Economic Analysis of Forest Residues Supply Chain Options to Produce Enhanced-Quality Feedstocks. Biofuels Bioprod. Biorefining 2018, 13, 514-534. [CrossRef]

15. Berry, M.; Sessions, J. The Economics of Biomass Logistics and Conversion Facility Mobility: An Oregon Case Study. Appl. Eng. Agric. 2018, 34, 57-72. [CrossRef]

16. Bergman, R.D.; Zhang, H.; Englund, K.; Windell, K.; Gu, H. Estimating Ghg Emissions from the Manufacturing of Field-Applied Biochar Pellets. In Proceedings of the 59th International Convention of Society of Wood Science and Technology, Curitiba, Brazil, 6-10 March 2016.

17. Riva, L.; Surup, G.R.; Buø, T.V.; Nielsen, H.K. A Study of Densified Biochar as Carbon Source in the Silicon and Ferrosilicon Production. Energy 2019, 181, 985-996. [CrossRef]

18. Dumroese, R.K.; Heiskanen, J.; Englund, K.; Tervahauta, A. Pelleted Biochar: Chemical and Physical Properties Show Potential Use as a Substrate in Container Nurseries. Biomass Bioenergy 2011, 35, 2018-2027. [CrossRef]

19. Bartocci, P.; Barbanera, M.; Skreiberg, O.; Wang, L.; Bidini, G.; Fantozzi, F. Biocarbon pellet production: Optimization of pelletizing process. Chem. Eng. Trans 2018, 65, 355-360.

20. Badger, P.; Badger, S.; Puettmann, M.; Steele, P.; Cooper, J. Techno-Economic Analysis: Preliminary Assessment of Pyrolysis Oil Production Costs and Material Energy Balance Associated with a Transportable Fast Pyrolysis System. BioResources 2010, 6, 34-47. [CrossRef]

21. Chen, X.; Zhang, H.; Xiao, R. Mobile Autothermal Pyrolysis System for Local Biomass Conversion: Process Simulation and Techno-Economic Analysis. Energy Fuels 2018, 32, 4178-4188. [CrossRef]

22. Mirkouei, A.; Mirzaie, P.; Haapala, K.R.; Sessions, J.; Murthy, G.S. Reducing the Cost and Environmental Impact of Integrated Fixed and Mobile Bio-Oil Refinery Supply Chains. J. Clean. Prod. 2016, 113, 495-507. [CrossRef]

23. Polagye, B.; Hodgson, K.; Malte, P. An Economic Analysis of Bio-Energy Options Using Thinnings from Overstocked Forests. Biomass Bioenergy 2007, 31, 105-125. [CrossRef]

24. Puettmann, M.; Wilson, K.; Oneil, E. Life Cycle Assessment of Biochar from Postharvest Forest Residues. In Waste to Wisdom; Consortium for Research on Renewable Industrial Materials (CORRIM): Corvallis, OR, USA, 2017; 50p.

25. Kizha, A.R.; Han, H.-S.; Paulson, J.; Koirala, A. Strategies for Reducing Moisture Content in Forest Residues at the Harvest Site. Appl. Eng. Agric. 2018, 34, 25-33. [CrossRef]

26. Sahoo, K.; Upadhyay, A.; Runge, T.; Bergman, R.; Puettmann, M.; Bilek, E. Life-Cycle Assessment and Techno-Economic Analysis of Biochar Produced from Forest Residues Using Portable Systems. Int. J. Life Cycle Assess. 2021, 26, 189-213. [CrossRef]

27. Puettmann, M.; Sahoo, K.; Wilson, K.; Oneil, E. Life Cycle Assessment of Biochar Produced from Forest Residues Using Portable Systems. J. Clean. Prod. 2020, 250, 119564. [CrossRef]

28. Severy, M.A.; David, J.C.; Kyle, D.P.; Anthony, J.E.; Arne, E.J. Performance and Emissions Control of Commercial-Scale Biochar Production Unit. Appl. Eng. Agric. 2018, 34, 73-84. [CrossRef]

29. Page-Dumroese, D.S.; Busse, M.D.; Archuleta, J.G.; McAvoy, D.; Roussel, E. Methods to Reduce Forest Residue Volume after Timber Harvesting and Produce Black Carbon. Scientifica 2017, 2017, 2745764. [CrossRef]

30. Shackley, S.; Hammond, J.; Gaunt, J.; Ibarrola, R. The Feasibility and Costs of Biochar Deployment in the Uk. Carbon Manag. 2011, 2, 335-356. [CrossRef]

31. ISO. Environmental Management: Life Cycle Assessment; Principles and Framework; International Organization for Standardization: Geneva, Switzerland, 2006.

32. ISO. Environmental Management: Life Cycle Assessments: Requirements and Guidelines; International Standardization Organization: Geneva, Switzerland, 2006.

33. Pre'Consultants. Simapro 8 Life-Cycle Assessment Software Package. Version 8. Plotter 12. Available online: https://simapro. $\mathrm{com} /$ (accessed on 15 May 2021).

34. SERC. Biochar Testing and Results Report Waste to Wisdom: Task 3; Schatz Energy Research Center (SERC): Arcata, CA, USA, 2016.

35. Cornelissen, G.; Pandit, N.R.; Taylor, P.; Pandit, B.H.; Sparrevik, M.; Schmidt, H.P. Emissions and Char Quality of Flame-Curtain "Kon Tiki" Kilns for Farmer-Scale Charcoal/Biochar Production. PLoS ONE 2016, 11, e0154617. [CrossRef]

36. US-EPA. Tool for the Reduction and Assessment of Chemical and Other Environmental Impacts (Traci)-Traci Version 2.1 User's Guide; Environmental Protection Agency: Cincinnati, OH, USA, 2012; 24p. 
37. Singh, B.P.; Cowie, A.; Smernik, R. Biochar Carbon Stability in a Clayey Soil as a Function of Feedstock and Pyrolysis Temperature. Environ. Sci. Technol. 2012, 46, 11770-11778. [CrossRef]

38. Budai, A.; Zimmerman, A.R.; Cowie, A.L.; Webber, J.B.W.; Singh, B.P.; Glaser, B.; Masiello, C.A.; Andersson, D.; Shields, F.; Lehmann, J. Biochar Carbon Stability Test Method: An Assessment of Methods to Determine Biochar Carbon Stability. International Biochar Initiative. 2013. Available online: https://www.biochar-international.org/wp-content/uploads/2018/06/ IBI_Report_Biochar_Stability_Test_Method_Final.pdf (accessed on 15 May 2021).

39. Manouchehrinejad, M.; Sahoo, K.; Kaliyan, N.; Singh, H.; Mani, S. Economic and Environmental Impact Assessments of a Stand-Alone Napier Grass-Fired Combined Heat and Power Generation System in the Southeastern Us. Int. J. Life Cycle Assess. 2020, 25, 89-104. [CrossRef]

40. Towler, G.; Sinnott, R. (Eds.) Chapter 9-Economic Evaluation of Projects. In Chemical Engineering Design, 3rd ed.; ButterworthHeinemann: Oxford, UK, 2022; pp. 305-337.

41. Campbell, R.M.; Anderson, N.M.; Daugaard, D.E.; Naughton, H.T. Financial Viability of Biofuel and Biochar Production from Forest Biomass in the Face of Market Price Volatility and Uncertainty. Appl. Energy 2018, 230, 330-343. [CrossRef]

42. Cheng, F.; Luo, H.; Colosi, L.M. Slow Pyrolysis as a Platform for Negative Emissions Technology: An Integration of Machine Learning Models, Life Cycle Assessment, and Economic Analysis. Energy Convers. Manag. 2020, 223, 113258. [CrossRef]

43. USDA-NRCS. Conservation Enhancement Activity; E384135z; United States Department of Agriculture, Natural Resources Conservation Service: Washington, DC, USA, 2019. 